\title{
CARTOGRAPHY IN TOURISMOLOGY - TOURISMOLOGY IN CARTOGRAPHY
}

\author{
Goran Barović ${ }^{1}$ \\ Duško Vujaćić
}

\begin{abstract}
Both cartography and tourismology are scientific disciplines that originated in geography. Until recently, it was considered that, along with other geosciences, they were only subdisciplines that deal with its individual segments in more detail. From the formal point of view, such theories can be justified to some extent, but essentially, we see that these are two very serious sciences with a wide range of scientific research competencies. Traces of cartographic and tourismological research can be found, from the oldest levels of development of human civilization when they developed under the auspices of geography to their later development as a discipline that studies and observes the Earth and its spheres from a cause-and-effect point of view. Since the separation from their „mother“ discipline and their further independent development, with specific scientific-research peculiarities, both cartography and tourism form a special way of studying the objective reality and interpretation of the observed. This paper will research the connection of these two sciences, which rely on each other, where appropriate solutions arise from mutual connections, which are in themselves answers to the questions asked. The specificity of the connection between these sciences is seen in the application of the cartographic method, ie enabling the perception of three important categories through the spatial, temporal and essential definition of the tourism specifics of the treated space. Cartography draws contents from tourism and tourism, in cartography and its numerous methods and means of expression, seeks the most expedient ways of presenting the obtained data.
\end{abstract}

Key words: cartography, turismology, cartographic method, cartographic means of expression.

\section{$\begin{array}{llllll}\text { CARTOGRAPHY IN TURISMOLOGY } & - & \text { TURISMOLOGY IN }\end{array}$ CARTOGRAPHY}

Both cartography and turismology are scientific derivatives of geography. Up until recently they were considered to be branches of geography among other geo-sciences that deal in detail with some of geographical segments. Formally, these theories can be justified but if we look at their essence we can see that they are two separate scientific disciplines with wide spectrums of scientific work. Traces of cartographical and turismologic explorations can be found in the oldest forms of human civilization when they developed under patronage of geography, as well as in more modern development when these sciences observe the Earth and its spheres from a causative point of view. By means of separation from „mother" science and further independent development with specific scientific characteristics, both cartography and turismology form a specific way of exploration of objective reality and interpretation of the observed data. This paper is dealing with the connection of these two sciences that rely on each other where from the connections we can see self-sufficient solutions. The specificity in the connection between these two sciences can be observed in the application of

\footnotetext{
${ }^{1}$ Assistant Professor, University of Montenegro, Filozofski fakultet, Nikšić, 81400, Crna Gora

${ }^{2}$ Teaching Associate, University of Montenegro, Filozofski fakultet, Nikšić, 81400, Crna Gora
} 
cartographical method and possibility of observing the three important components through spatial, temporal and essential definition of turismologic specificities of the space in question. Cartography takes contents from turismology, while turismology finds the most appropriate ways of presentation of their data in cartography.

\section{PREFACE}

Cartography is the science of maps and studies the basic properties, contents, ways of expression, as well as the methods of production, publishing and usage of maps. It has a wide application in all spheres of human activity. The question is whether we can find a single human activity where cartographic expression cannot be found as a way of communicating the results of research or any kind of transmission of the messages. The most obvious means of presenting various types of content is certainly the map, although in cartography there are several ways of presenting content from the geospace. The map has become a universal language for presenting various contents. How to define a map? According to the definition accepted at the 10th General Assembly of the International Cartographic Society, a map is "A coded image of geographical reality that shows selected objects or properties, created by creative authorial choice, and used when spatial relationships are of paramount importance.". The connections between cartography and tourismology implies a very wide range of activities which are subsumed under one name - tourismology. Turismology is a science that studies "relationships and phenomena arising from the travel and stay of visitors ..." (Pasinovic M, 1984). It is this definition, which completely defines tourism, that experiences its most obvious presentation through cartographic presentations. When planning any tourist visit, the first contents we explore are maps, for example: searching for the most optimal route to the determined destination, selection of motives that are interesting in the chosen destination, followed by finding appropriate cartographic content to locate selected motives; one of the other possible uses is, finding an alternate route to return to the home destination. We can almost be sure that there is no tourist movement where the map does not appear as accompanying content. Accordingly, a large number of maps belong to the group of tourist maps, on the cartographic side they are classified in the group of thematic, analytical and synthetic maps. Analytical, thematic tourist maps include those that show one phenomenon, while other contents are given only for information, in order to coordinate the rest of the content. Synthetic maps show several related topics that are related to the mapped space, but none of them stands out in relation to the other ones, so all are ranked at the same level. This paper also presents a brief explanation of the most commonly used methods and cartographic means of expression used to make maps. Also, as an inevitable part of research, some positive and negative examples of tusic maps showing contents from Montenegro will be analyzed.

Important information to be communicated on a tourist map depends on the target group for which it is intended. There are two important questions to answer when making a tourist map.

- Who is it for - a foreign or domestic guest

- What to show - general characteristics of the space or specific contents In the first question, it is important to distinguish between a foreign and a domestic guest where the level of information to be communicated is different. For a foreign guest, first 
of all, maps should be prepared that show the contents of the group of maps that define the tourist-geographical position. First of all, it is important to accurately present the position in the geographical coordinate system, which is connected by many important facts: the position of Montenegro towards important spatial units from which to attract potential visitors, the position on the Balkan Peninsula, access to the Adriatic Sea.

\section{CARTOGRAPHIC METHOD IN THE PRESENTATION OF TOURIST CONTENT}

Cartography, as a scientific discipline with a wide range of possibilities for scientific presentation of different types of content, has found its expression in the presentation of content related to the tourism industry. In accordance with the establishment of connections with the scientific discipline from which it draws the contents that it will present, cartography primarily establishes its own, cartographic method. In addition to the cartographic method, as a universal one because it covers all aspects important for the display of tourist content, a standard range of general cartographic methods is used for displaying content on thematic maps. In addition to such a wide range of methods, great possibilities are represented by numerous means of expression, which serve us to present the selected content in an adequate way. Knowing the possibilities of cartography and a wide range of topics related to tourism, this opens up the possibility of achieving unbreakable links between cartography and tourism. Cartography has found in tourism a very suitable ground for drawing various contents that will allow it to express itself in complete scientific creativity. In contrast, we have toursmology, which in cartography finds the perfect space to display all the necessary attributes that need to be highlighted through a wide range of thematic, analytical and synthetic maps. In this constellation of theses, we come to the conclusion that cartography has found the perfect space to express its capabilities in tourismology, and that tourismology has a universal language for the presentation of tourist motives in cartography.

Through the realization of the cartographic method, we come to the most obvious, most accurate and most understandable image of a space with all its specifics. The specifics of a map are created during a two-phase process. The first phase is the mapping of the treated space, and the second phase is the process of obtaining data from the mapped space. (Lješević M. 1981),

- $\quad$ Mapping, ie. extracting part of the geospace from the complex of reality. In this process, it is important to collect as much data as possible on tourist motives and all other elements in the area that are important for tourist movements. This procedure, which must be very precise, clearly defined and comprehensive, will form a database from which the tourist map, as the main product of the work, will include content that will present the mapped space to the map user in the best and most obvious way.

- The process of obtaining data on reality, or in this case, the perception of the tourist values of the treated area represents the process of analysis of the mapped content and the choice of motives that are interesting to the map user. The advantage of this methodological procedure is that it enables the knowledge of a larger volume of reality than the amount of information interpreted by primary mapping. In tourist maps, this is an analysis and synthesis of the displayed content in order to form an overall picture of 
the mapped space, which gives us the opportunity to choose topics that are interesting to the user and plan the most optimal route to consume the selected content.

The cartographic method enables the consideration of the following scientific categories:

$$
\begin{array}{ll}
- & \text { Spatial definition, } \\
- & \text { Time definition and } \\
\text { - } & \text { Essential definition. }
\end{array}
$$

Spatial definition enables the positioning of geospatial elements in relation to the accepted spatial system. For example, defining the positions of tourist motives, important for the observed area, which were chosen to be applied to the map. In this way, an important possibility is given, defining the mutual localization of the treated elements, because it greatly facilitates the planning of a tourist trip. Based on this, we can do further data processing, and discovery, according to the interested tourists, of more or less important content, as well as analysis that will offer proposals for solving possible problems. This is a very important element that opens wide possibilities for further analysis of mapped content.

Time definition is expressed in two ways: by determining the time provision for mapped content (characteristics of tourist motives at the time of observation - eg: summer or winter tourist motives; weather forecast maps for the requested date, ...) and localization of tourist motives for a defined time period (maps with significant archaeological sites, maps with locations of significant historical events related to the mapped area, weather forecast for a certain period of time ...). This type of definition is of particular importance for the presentation of tourist values for the simple reason that they can be crucial for tourists to plan a stay in a particular country or a geographically narrower locality.

Essential definition is a qualitative and quantitative determination of individual and group properties of the mapped territory. Insight into the offered maps, provides an opportunity to plan a quality trip and stay in the selected area, because a tourist trip is a fit of a wide range of activities and needs to meet the requirements of the interested tourist. A responsible tourist carefully chooses the itinerary, studies the tourist values of the place of residence as well as the return to the place of permanent residence (quality of roads, restaurants, gas stations, health care, calendar of events, shops, banks, rest areas, cultural and sporting events, customs and laws etc...)

The maps that show the contents related to tourismology belong to the group of complex thematic maps. A very wide range of cartographic methods of presentation, as well as a large selection of cartographic means of expression give a chance for high quality, accurate, obvious and clear presentation of all indicators that can present tourist values that may be of interest to potential users.

\section{METHODS OF MAPPING}

There are two methods that are used to display the content on thematic tourist maps. To map a phenomenon means to show on the map its position and to a greater or lesser extent its' quantitative and qualitative characteristics. The totality of conditions that enable the appearance of mapping is called the mapping method. After choosing the 
method, mapping is realized by applying various cartographic means of expression. No method of mapping is limited to the use of only one means of expression, but still each is destined for a limited number of means of expression. Each one individually gives the opportunity to be used for some kind of cartographic presentation of content related to tourism.

In General Cartography, several methods of cartographic presentation are defined that are used for presentation of various types of content. Tourist maps are synthetic maps that have a variety in the types of content that tourists may be interested in. Almost all known methods of displaying content on maps can be used to display some of the topics that can be treated as tourist or have an immediate or indirect connection with the tourism industry. These methods are: qualitative zoning method, areal method, line motion method, sign method, map diagram method, carthogram method, vector method, isoline method and point method.

Two methods are used to display the content on maps that represent elements from the space that are directly or indirectly related to the display of attributes related to the tourism industry as well as objects, phenomena and processes that are more or less correlated with it. One is the method of lines of movement and the other is the method of pictorial or symbolic signs.

The line of motion method shows the directions to some phenomena related to tourist centers, such as various types of traffic, (aircraft, road, nautical) forecast of climate elements (wind,...), sea currents, etc. Various combinations of line thickness, line type (solid, dashed, dotted) and its colors can be used to fully define the qualitative and quantitative characteristics of the mapped phenomenon.

The method of signs, pictorial or symbolic uses silhouettes or drawings of the natural appearance of some objects or phenomena. Due to the ease of interpretation of the displayed content, this is a very popular way of presenting the selected content. An added value is that this method provides clear readability and eliminates language barriers that can sometimes be a limiting factor in understanding content. (Pavišić, N. 1976)

\section{CARTOGRAPHIC MEANS OF EXPRESSION}

The map is created by applying selected cartographic means of expression. This is simply defined as the representation of selected elements from geospace in graphical form. They enable the application of the chosen mapping method. The most commonly used cartographic means of expression are: boundary lines, colors, simple geometric signs, symbolic signs, scalars and vectors, direct explanation, numerical letters, areas and the number (quantity) of elementary signs. (Burić M. Barović G. 2005)

Symbolic signs are most often used on tourist maps. These are in fact miniature drawings that represent in the depiction of phenomena and processes that are the subject of the presentation of tourist facilities. When it comes to displaying tourist content, it is most often a display of tourist facilities, sports fields, bathing areas, hunting and fishing areas, facilities with cultural content, service activities (restaurants, gas stations, pharmacies), etc.

No cartographic means of expression is exclusively related to one mapping method, but can be applied with more or less success to several mapping methods. The means of expression were developed in accordance with the tasks presented, with the aim of 
fulfilling two important requirements that are set before almost every map, and those are - metrics and clarity. As a rule, one means of expression fully corresponds to either metrics or clarity, so in relation to the type of map, the appropriate cartographic means of expression that best suits the purpose of the map is chosen. Metricity can only be achieved when objects displaying the same content are displayed. The choice of means of expression is defined by the theme of the map. For example in the case of making tourist maps, which show only one of the elements, usually only one is used, but when making synthetic maps, we use multiple other cartographic means of expression. Allof these are used in terms of which parameter is important for the user, metric or clarity. (Peterca M. et al. 1974.)

An important segment of thematic climatological maps is their legend. On each map, a legend with all the topographic signs used to display the content should be displayed in its non-framed area. Therefore, the correctness of the choice of means of expression is of paramount importance. The purpose of the thematic map is the basic criteria for resolving this issue. In the case of thematic maps that have a wide application, e.g. climatological maps, most of the means of expression used to present the content are easily recognizable and their appearance is associated with the predicted phenomenon that is presented. For the creation of specialized thematic maps that have a narrow professional application, expressive means can be used that are not widely used, but are clear to users and allow further work on the analysis and processing of the presented content.

\section{MOST COMMON CONTENTS ON TOURIST MAPS}

The most common and one of the first tasks that must be shown on tourist maps is the tourist-geographical position of the mapped area. The interested user of the map must be shown the position of the tourist center in a clear and precise way in order to be able to reach the desired destination that is the subject of his interest in the easiest and fastest way. The map should contain the directions of movement and types of traffic that are available to the potential visitor in order to have more choice when organizing the trip. If possible, the tourist map should also contain the position of the geographical location of the mapped territory, so that the user of the map would be familiar with that type of content. This part is most often solved by inserting map s of a larger territory where the position of the territory treated by the tourist map, relative to a wider geographical area, is given on such a map. This is done in such a way that the territory to be highlighted (if we show the area of Montenegro, its territory is painted in a strong tone, eg red) is painted with some intense color, and the surrounding area is shown in white or a version of light tones with minimal content that will provide the map holder with information about the area in question (only state borders or capitals of countries).

The size of the territory and the characteristics of borders and border crossings are also a mandatory part of the contents of the maps that represent tourist facilities. As an important element in the space, map users who come from abroad to the country whose territory is the subject of tourist mapping must be familiar with this important content for several reasons.

Depending on the topic of the content on the map, tourist maps also include natural tourist values that are specific to the mapped area. This type of content has a wide range of topics that need to be carefully selected and presented in a quality way. This group 
includes topics related to geomorphological characteristics of space, (mountains, canyons) hydrographic characteristics (rivers, lakes) characteristics of flora and fauna, characteristics of the coastal belt with emphasis on characteristic areas. On tourist maps, they are presented in anthropogenic values of space, which can also be a tourist motif, if they are: archaeological, monumental, artistic, ethnographic, etc. values that are according to some characteristics specific to the mapped space.

\section{CONTEMPORARY TENDENCIES IN THE MAKING OF TOURIST MAPS}

The connection of cartography with informatics has greatly contributed to the improvement of the procedures carried out in the production of maps. There are a large number of advantages that have arisen as a consequence of these activities, although the occurrence of severe negative consequences has also been recorded.

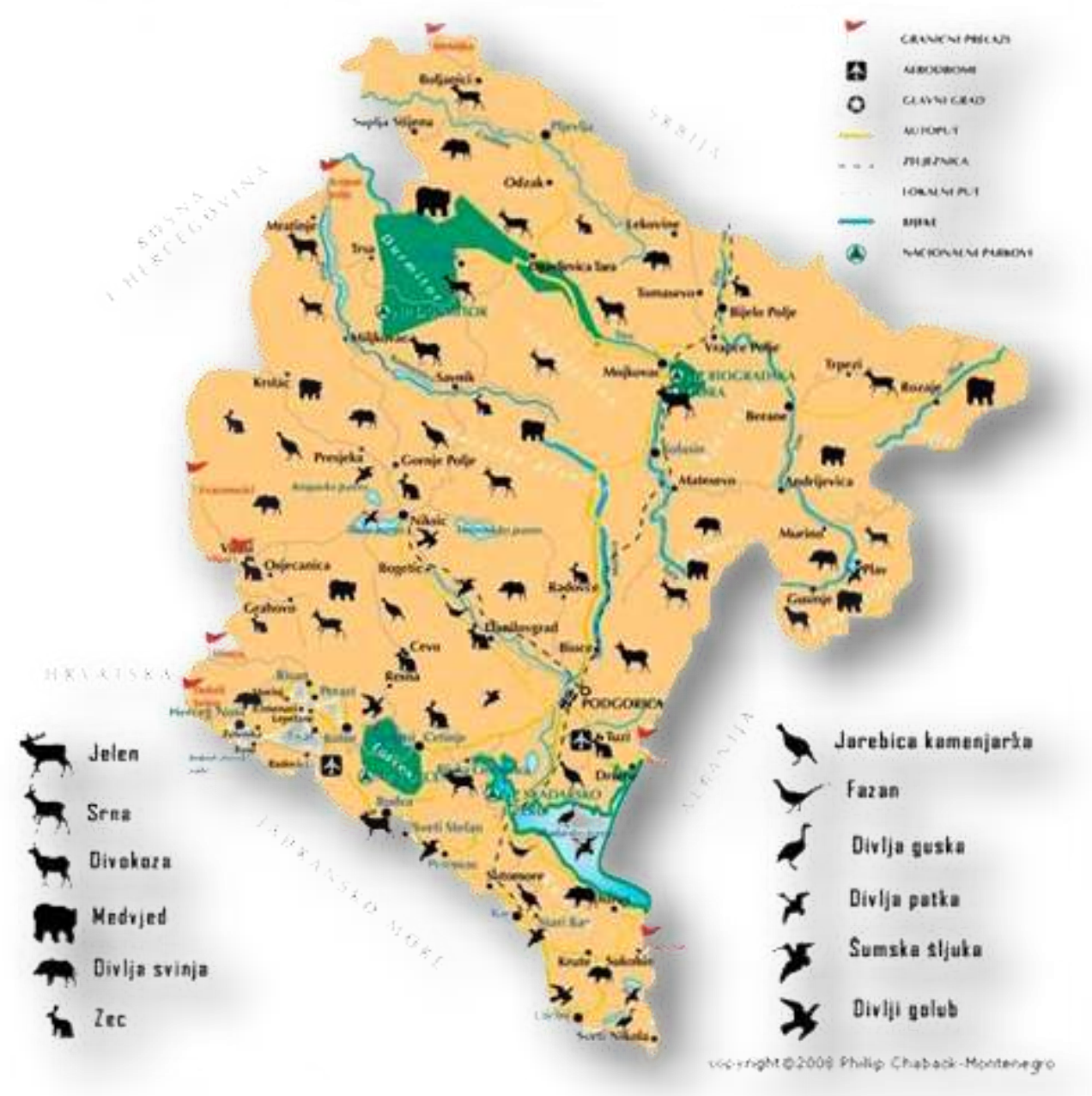

Figure 1. Map of the hunting alliance Source:

http://www.lovackisavez.me/mne/lovna_divljac.php, accessed November 1, 2020. 
In the earlier period, the production of tourist maps was done by a limited number of publishers who had a high degree of responsibility for this very serious business. The most important issuers of tourist maps were national tourist organizations, large economic entities that were engaged in the tourist economy. Most maps from that period can be highlighted as good examples of maps that show the elements of space that can be part of the tourist offer.

The cartographic presentation of the tourist contents of Montenegro was most often dealt with by the National Tourist Organization, which, as the supreme state institution for the promotion of tourism, issued several maps whose properties met the eternal conditions placed before each map. Selected tourist motifs are applied on them using sybolic cartographic signs. Also, basic data from the group of mathematical and editorial elements are given, as well as certain contents in the out-of-frame content of the map, a high quality legend and an inserted map of a larger territory.

From the group of good maps that can be classified and the type of tourist offer is the map issued by the Hunting Association of Montenegro. Sybolic signs were also used on this map, in the way that pictures of animals that are positioned in the territories they live in are given. It is also a positive to point out the legend in which each picture of the animals shown on the map is marked with their name. (Fig.1.)

Unfortunately, today, in places where tourist maps are distributed, more bad examples can be found than those that represent the tourist potentials of Montenegro or certain parts of it in a quality way. The biggest problem is that they contain content that can lead the map user astray and give incorrect information about certain parts of the mapped territory. This problem has become more pronounced in the last few decades when a large number of private publishers appeared, which, unfortunately, printed and distributed maps with tourist content without any control. These publishers, for various reasons, usually force some content at the expense of others, choose the content according to the criteria they set themselves, do not take into account the mathematical basis, editorial data and additional elements. Some of this data is not stated out of ignorance of the rules of cartographic display, and some of it is not intentionally shown in order to hide the identity of the publisher.

Showing the territory of Montenegro is a common motif on "tourist maps" which have major shortcomings in their content. One of these is a map that could not determine who the publisher was, when it was issued, etc. The only information that can be read on the map is the marking of the cataloging that was done abroad. There are several errors on this map, but we will list only a few here: the categorization of the settlements was not done according to the same standard, ie. cities with the same or similar population are presented in different ways; the map is enriched with numerous photo attachments, with which there is no information about the author, precise location, name of the locality, overlap with the markings, without editorial data, etc.

The territory of the capital city of Podgorica is a common motif on the maps that are issued by TOP (Tourist Organization of Podgorica), which is the biggest problem. The map that is the subject of processing in this paper also abounds in numerous shortcomings as well as incorrect or incorrectly stated content. Symbolic signs were often used to display the content, which are often not clear to the people of Podgorica themselves, religious buildings are not categorized in the same way (some have full names and some do not), shopping malls are not evenly displayed (some are shown and others are not mentioned), there are symbols for contents that do not belong to the 
mapped territory, marked parts are without the complete information of the city where the user of the map can be misled (Čepurci cemetery is shown as a green area), etc. (Fig. 2.)

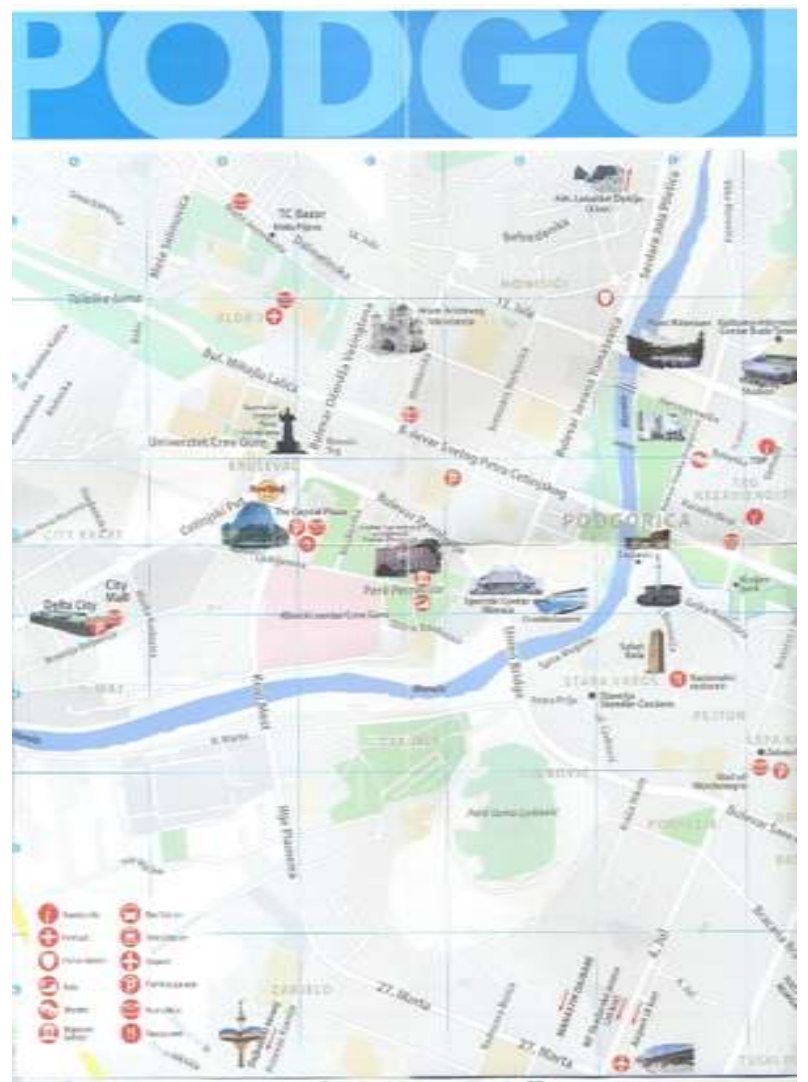

Figure 2: Map of Pogorica (TOP - no other data)

When we look at the overall situation in the presentation of tourist content on the maps of various publishers, one gets the impression that it may be better for them to not exist than to present them in this way. Unfortunately, the solution to this problem is not in sight, because there is no institution in Montenegro that controls this way of presenting tourist content. Attempts have been made with letters to state bodies, various institutions, comments in the media, but unfortunately the issue continues as before, so no results are visible.

\section{CONCLUSION}

The aim of this paper is to present a precise analysis of determining the connection between two areas that are very interconnected. Of the numerous methods and cartographic means of expression, those that are most suitable for presenting tourist motifs have been clearly singled out. The contents that should be on the tourist maps are defined also, as well as the modern tendencies in the cartographic presentation of tourist contents. Some positive and some negative examples of cartographic 
presentation are pointed out, as well as some of the ways to influence the raising of the quality of cartographic presentation of tourist motifs.

\section{LITERATURE}

1. Burić M, Barović G., Basics of cartography, Philosophical faculty of Nikšić, 2005. (102-106)

2. Pasinović M., (1984) Basics of tourism, Univerzitet Veljko Vlahović, Titograd, $1984(12-15)$

3. Lješević M. (1981) Cartographic method in the system of scientific methods and its place in geography. Globus, br.13. SGD, (52-60)

4. Pavišić N. (1976), Basics of cartography, Obod, Cetinje. (163-169)

5. PetercaM., Radošević N., Milisavljević S., Racetin F., (1974) cartography, VGI, Beograd (405-408) 